Pbilosophia Philosophia Scientiæ

Scientie Travaux d'histoire et de philosophie des sciences

$17-3 \mid 2013$

Tacit and Explicit Knowledge: Harry Collins's

Framework

\title{
Refining the Tacit
}

\section{Harry Collins}

\section{(2) OpenEdition}

1 Journals

Electronic version

URL: http://journals.openedition.org/philosophiascientiae/895

DOI: 10.4000/philosophiascientiae.895

ISSN: $1775-4283$

Publisher

Éditions Kimé

\section{Printed version}

Date of publication: 1 October 2013

Number of pages: $155-178$

ISBN: 978-2-84174-641-5

ISSN: 1281-2463

Electronic reference

Harry Collins, « Refining the Tacit », Philosophia Scientiæ [Online], 17-3| 2013, Online since 01 October 2016, connection on 06 November 2020. URL : http://journals.openedition.org/philosophiascientiae/ 895 ; DOI : https://doi.org/10.4000/philosophiascientiae.895 


\title{
Refining the Tacit
}

\author{
Harry Collins \\ School of Social Sciences, Cardiff University, Wales (UK)
}

\section{General}

For one's work to be made the topic of a special issue of a journal is an enormous honour. That it is a philosophy journal makes the honour still greater since I am not a professional philosopher. Though I have no technical and scholarly training in philosophy, I have, however, learned hugely from a certain style of philosophical work, and from the start of my career in sociology, the later philosophy of Wittgenstein has been a dominant role model. Thus I thank the editors for providing this context and I thank my critics for being willing to allow the light-ray of their continuing work to be at least slightly diverted by the gravitational field of my book. Not that all the light rays have come especially close. Two of the "critiques", those of Lynch and Pinch, are more in the way of saying "I'm over here and you should be over here too". At the other extreme Turner has gone straight for the core of the book and tried to explode one of its most basic principles, while Soler \& Zwart have tried, and to some extent succeeded, in moving its orbit. Tim Thornton is somewhere in between. I'll start with the more distant beams and work inwards to Thornton, I'll then discuss Turner and finish with Soler \& Zwart.

\section{Pinch and Lynch (and Doing) and the big shift}

There seems almost to be a "Cornell School" of tacit knowledge because both Pinch and Lynch want me to switch all or some of my attention from what tacit knowledge is to how it is socially constructed or performed. I say a Cornell School because this was exactly the burden of the review of the book, published in 2011, in Social Studies of Science, by Cornell graduate student 
and researcher, Park Doing [Doing 2011]. Lynch was the editor of the journal at the time and I am surprised that he does not cite Doing's article because his main point more or less exactly repeats what Doing says. Pinch's article also goes in the same general direction and he too could well have cited the review. Both do cite earlier papers by Doing. So we can say that the Cornell School favours a neo-Marxist approach, or interest theory, or something close, in the analysis of tacit knowledge. I will start, then, with the Cornell School, including Doing's review which, as can be seen in the bibliography, is available online, and then go back to particular points in the Pinch and Lynch papers.

In his paper Trevor Pinch says that I am engaged in employing one of my favourite tactics, "compartmentalization", in order to resolve the paradox of the relativism of the experimenter's regress and the realism of the notion of there being some substance to tacit knowledge (and as he might have said, knowledge in general). It is true that compartmentalization is one of my favourite strategies but I do not think I am deploying it here. I have mainly employed compartmentalization to try to weaken the obsession of many in the field of science studies with reflexivity. Reflexivity, it seemed to me, threatened to paralyse everyone because they felt they could never put forward any sure finding about the natural sciences from their position within the social sciences without betraying their relativist credentials - given what they were saying about natural sciences they felt that they were not entitled to make positive claims. Malcolm Ashmore was the most obsessed and agonised but, at one time, it was a rapidly spreading affliction [Ashmore 1989]. So, just as Pinch points out, I said one should compartmentalize one's activities into realism when one was being a social scientist but relativism in respect of the productthe analysis of science. I argued that without compartmentalization none of us could live even our ordinary lives.

But I do not think I try to resolve the apparent contradiction that Pinch points to via compartmentalization. In the early days of my work I was always deeply worried about that contradiction but nowadays I think I have a satisfactory solution: it is a matter of the direction of attention; if I pay attention to what is in front of me I see one thing, if I turn round and look in the other direction, I see another thing, but these things are not in tension, they are just different things.

To be clear, let us go back to the early days and see what was going on. In 1974, I published my first paper on the TEA-laser and in 1975, I published my first paper on gravitational waves: the second paper introduced the concept of the experimenter's regress though I did not think up the name for it until this early work was drawn together into Changing Order [Collins 1985/1992]. Shortly after the publication of those first two papers I realised that there was a contradiction at the heart of them: the realist 1974 paper was the basis of the relativist 1975 paper. For a long time this scared me and I kept quiet about it, waiting for the devastating criticism to come. But it never did come (at least, not until now). The worst of the crisis was over by about 1981 when 
I decided I was not a philosophical relativist but a methodological relativist and this took the logical force out of any contradiction.

Pinch's critique has now forced me to think again. In 2002, Evans and I introduced the idea of three waves of science studies and, in particular, the new Third Wave. At the heart of the Third Wave was a move from the analysis of truth to the analysis of expertise and experience. The rest is history - a very unpleasant history to start off with and a quite pleasant and productive history now (e.g., see www.cf.ac.uk/socsi/expertise ). I am now going to characterise the Third Wave move in a slightly different way: it was a shift in attention from the interpretative flexibility of words and things to the affordance (or fixedness) of words and things. It was a shift from looking at how procedures and languages didn't work to how procedures and languages do work. There is no clash here. When I say to you, "pass me a knife", it may be that you will interpret this as a request for a dagger so I can stab my enemy in the course of a fight or it may be that you will pass me a knife to go with my fork so I can eat my dinner - such is the flexibility of language - but it is vastly less likely (though not completely impossible), that you will interpret the string of words as meaning "the top lead of a TEA-laser must be less than 8 inches long"- such is the affordance of language. The Second Wave concentrates on the flexibility of the interpretation while the Third Wave concentrates on the fixedness of the interpretation and these are no more in logical conflict than the view from in front of me and the view to the rear. Of course, there is some logistical tension because one cannot look in both directions at once: you have to choose what to look at. It was a failure to appreciate the lack of logical tension that led to the early unhappy history of the Third Wave (at least that is the charitable interpretation); we continually said that the Third Wave was compatible with the Second Wave but our critics were determined not to hear. The Third Wave must be compatible with the Second Wave because otherwise it would simply be the First Wave revisited - which is one of the things our critics say. The hard bit about the Third Wave is to make it possible to say something positive about the role of science without sacrificing all the wonderful insights that came to light under Wave 2. The first move in accomplishing this is turning attention to skill and expertise, the second is thinking about affordance instead of flexibility, and the third, if I have my way, is going to be looking at science as a moral enterprise ("elective modernism").

I now want to recruit the 1974 paper, and my subsequent work on tacit knowledge and artificial intelligence into the Third Wave. I have, as it were, "been speaking prose all my life, and didn't even know it!", because the term, "Third Wave", did not come along until 2002 and the idea of it being a potential shift of attention across all the social sciences and humanities did not come along until right now. So there is no need for compartmentalization because there is no logical contradiction to be resolved.

We are now in a position to make a general response to Pinch and Lynch and Doing. There are, of course, ways of analysing expertise as a matter of reinforcing professional interests, or "performing the notion of skill", but 
to cleave to them would simply shift attention back to flexibility and away from affordance. Consider Trevor Pinch's daughter: tell us, Trevor, was there sufficient interpretative flexibility associated with her performance for it to be the case that throughout her entire piano-playing career to date she had really been totally incompetent and only awarded those superior marks and gold cups because the teachers were scared of you as a powerful Cornell professor? There is no need for an answer. It is logically possible but at this point I am sure you, Trevor, are thinking of your daughter's skill and the narrow affordance it offered to the assessor (playing the piano that beautifully she must have been at least "excellent" or "superior"), not the flexibility of interpretation so it is just a matter of what you choose to look at.

\subsection{Pinch in detail}

First I would like to thank Pinch for his generous introduction and description of the book. One could not ask more from one whose duties are criticism. Then I have to bite the hand that feeds me with a nasty technicality: At one point Pinch asks: does Collins want to buy into the "tacit knowledge regress"? The answer is that I have no choice since the "tacit knowledge regress" is the experimenter's regress. I argued from the outset that the reason scientists could not be sure who had properly repeated another's experiment was because it required tacit knowledge to make an experiment work and tacit knowledge was invisible in its transmission and possession.

To continue gnawing at the fingers, I did not really understand what Pinch was arguing in his analysis of the two scrambled passages of text. "Yes", there may be many other cues that we use when we decide whether or not to read on but this seems to me just pointing out some imperfections in the "demonstration" rather than anything deep. More important is the claim, and I am sure it is true, that some human editors would try to correct the text. This is a common response to critics of artificial intelligence but was answered in 1974 by Joseph Weizenbaum, the inventor of ELIZA. He pointed out that an AI device that was said to be capable of mimicking a human could not be one that would mimic an incompetent human because an electric typewriter just sitting and humming could mimic the capabilities of some humans. That some human editors would understand what was needed but no machines is all that is required for the example.

Pinch points out something that I had not noticed about the book: there are far fewer examples of Collective Tacit Knowledge than of the other kinds. Pinch wants to make this out as telling us something but the reason is mundane. The chapter on CTK was much harder to write than the others but only because I was so familiar with the material that it was hard to work up the energy; in contrast, the other chapters were exploring new things. Without using the term, I have been writing about Collective Tacit Knowledge for most of my academic life. Anything that uses language as the example is about CTK 
and anything that is a polimorphic action-and The Shape of Actions is full of examples of polimorphic actions - is an example of CTK. There are then, lots of examples of CTK in my work if there are few in TEK [Collins 2010, hereafter TEK]. Here, then, I think Trevor is "barking up the wrong tree".

On cycling in the Netherlands and driving in traffic, Pinch, once more, invokes the difficulty of knowing whether there is real tacit knowledge at play or if it is just a way of belittling "outsiders"? Again, sometimes it will be the latter - there is enough interpretative flexibility - but unless Trevor thinks he could drive in China without alarms, and I certainly do not, there are also occasions when the example affords an analysis in terms of affordance. Whether you choose flexibility or affordance is up to you: in any case, I do not think social science allows you to tell an honest salesperson from a crook so I see no reason why the Third Wave should be able to do it. To use a concept does not require that one can infallibly identify all instances of its occurrence.

It is true that there is something more systematic to be said. When knowledge is under serious dispute, as in the circumstances of the experimenter's regress, then interpretation is more easily afforded than affordance. And that is why it is so hard to work out how to make policy decisions in respect of disputed science. In Cardiff, our approach to policy has to be essentially normative: we think using the advice of experienced experts is better than tossing a coin but we cannot really explain why. The argument is based on a kind of self-evident concept of what is best where "best" is a moral term. In Cardiff we are now moving even further, toward "elective modernism" where scientific expertise is valued over other kinds of expertise because of the values and aspirations of the (ideal) scientific community. ${ }^{1}$

When the knowledge is not disputed an affordance approach is more readily afforded than a flexibility approach. Thus there is no real problem in the case of Trevor's daughter. Trevor is a good enough appreciator of music to engage in the "downward discrimination" (see Periodic Table of Expertises in [Collins \& Evans 2007]), that enables him to understand that she is not bottom of the class and he is good enough at understanding our society and the role of experts in it to know that her teacher ought to be able to execute still more reliable downward discrimination. But, like any good "Wave 2er", he also knows how to doubt it: he has two sets of resources. The first set is his training in sociology of scientific knowledge, which has taught us how to doubt anything we take a fancy to doubting. The second resource comes simply from the fact that, as explained in Rethinking Expertise [Collins \& Evans 2007], those who are on the receiving end of downward discrimination tend not to recognise its force. During the UK's public debate over genetically modified organisms (GMOs) a member of the public claimed that because gene manipulation was aided by radioactive markers, GMO crops would be radioactive. Even a person with

1. In Mertonianism, the efficacy of science came first and the values followed-it is only under these norms that science can be efficient. In elective modernism, the values come first irrespective of efficacy. 
as little knowledge of biology as me could tell that this was not true but I doubt the objector could be convinced: "they would say that wouldn't they!" More seriously, it takes little expertise to understand that Andrew Wakefield's claims about the relationship between MMR vaccine and autism were based on nothing and it was very easy to explain but, tragically, those who believed in the link remained unconvinced.

\subsection{Lynch in detail}

I start with an error made by Lynch that is also made by Turner (below). Lynch says, in a rather strange and convoluted sentence, that

the core category of socially founded knowledge defies the very possibility of explication in a foreseeable future in his [Collins's] version of tacit knowledge. [This volume, 62]

What I say is simply that we cannot foresee how CTK could be explicatedit is currently unforeseeable - but that does not make it impossible. Why does Lynch say that I deny "the very possibility of explication in a foreseeable future" when he could have said: "Collins says he can't see how to do it"? It seems to be to prepare for the next paragraph which begins:

Collins faces a formidable challenge in his attempt to specify types of knowledge that are beyond explication in any foreseeable future. [This volume, 62]

"Any foreseeable future": what's that? All I talk about is not currently being able to foresee. Furthermore, I neither promise nor make any attempt to specify types of CTK, I just say it is all CTK. Here Lynch simply fails to engage with the book which puts a lot of effort into exactly defining the meaning of "cannot".

To get back to the main thrust of his piece, Lynch advertises that his "questioning extends to the very coherence and reality that Collins attributes to the overall 'terrain' of tacit knowledge". That's pretty exciting stuff so it is disappointing that he pulls back only a few lines later:

[...] its marginal relations to conceptions of explicit knowledge are crucial for understanding the meaning (the uses) of tacit knowledge - such relations constitute the relevance of tacit knowledge. Among the various uses of the concept of tacit knowledge are polemical uses that serve to enhance and defend the autonomy of academic and non-academic professions. Consequently, my aim in the remainder of this paper is to examine what is done with the notion of "tacit knowledge" rather than to define and classify what it is as a substantive domain. I will leave it to readers to decide if my treatment simply differs from Collins's or whether it reveals a basic misconception of the phenomenon on his (or my) part. [This volume, 58$]$ 
It turns out to be left to the reader to decide how radical Lynch's approach is. Well, I am a reader and it will be obvious by now that I do not think anything radical is going on here; what is going on is a Park Doing-like preference for looking at the way people use the notion of tacit knowledge to strengthen their claims to professional excellence. Of course they do! But people also use the concept of explicit knowledge to strengthen their claims to professional excellence. Go into your doctor's office and you will see certificates on the wall attesting to the formal training they have received. Does that mean we need a radical reinterpretation of the notion of explicit knowledge? If we do it is not for want of trying. Is it any kind of revelation that professionals use their displays of qualifications indicating their explicit knowledge to place barriers to entry around their professional domains? I do not think this is new and I do not think it disqualifies the study of explicit knowledge and its kinds. Why should such a "revelation" work that way for tacit knowledge?

Lynch says that this interest theory interpretation of tacit knowledge would be:

a shift away from philosophical debate about what can or cannot be made explicit, in principle or in practice, and toward studies of what counts - and, equally important, what does not count-as tacit knowledge in specific historical and contemporary circumstances. [This volume, 58]

Just to underscore what is going on, try the same claim on explicit knowledge: "an interest theory of explicit knowledge would be":

a shift away from philosophical debate about what can or cannot be tacit, in principle or in practice, and toward studies of what counts - and, equally important, what does not count - as explicit knowledge in specific historical and contemporary circumstances.

Sure, either of those projects are viable but they aren't exactly radical. The "specific historical and contemporary circumstances" we have experienced since the middle of the last century are such that it was radical to do such an analysis half-a-century ago but now it is just going on the same old way. Such analyses are nowadays "normal science" in STS. It seems to me that in the particular historical location we find ourselves in now the radical thing for a social scientist of science to do would be precisely a shift toward a "philosophical debate about what can or cannot be made explicit, in principle or in practice" while trying to retain everything we know from the last half-century (Wave 2), about context-specificity. This would be a hard thing since Wave 2 has been looking in the other direction for half-a-century. The political and institutional position of Wave 2 in the universities is nowadays far more powerful and conservative than Mertonianism ever was and it is time for Wave 2ers to stop claiming they are radicals.

Lynch's "radical" approach also takes us all the way back to Harold Garfinkel. Here is how he sets out the message of Garfinkel for tacit knowledge: 
[...] the situational, interactional, and temporal relations that arise in the course of the practices of instructed action constitute the very relevance of tacit knowledge [TEK]. As Garfinkel's students discovered when performing an exercise to follow directions for getting from a starting point to a destination in a city, the difficulties and contingencies they encountered were particular and mundane: they did not enter a "dimension" of tacit knowledge, instead they ran into a stream of difficulties during their ongoing attempts to reconcile the sketchy details of their directions with the unfamiliar and overwhelmingly dense "lived" course of the journey. [This volume, 60-61]

Followers of Garfinkel often seem to want to have their cake and eat it too. Look at the description of the students' experience. It is not presented as something that happened to a particular group of students at a particular time. It does not say that "at 10.30 on 16 May, 1965, John and Jane Doe were instructed by Harold Garfinkel to follow an instruction that would take them from his office in UCLA to the seventh bus stop along the side of La Brea tar-pits and they ran into some difficulties following the instructions". Instead it says having difficulties following instructions always happens! As Bruno Latour and Steve Woolgar explain in Laboratory Life [Latour \& Woolgar 1979], the indicator that science - generalization - has been achieved is the removal of modalities (descriptions of the particular contingencies of persons, places and times) from the descriptions of experimental activity. Here we have experimental activity and the paragraph clearly points to the fact that the difficulty of following instructions described here is a general feature of all instruction-following, not a contingency that happened to John and Jane at 10.30 on 16 May 1965. Is Lynch founding the new ethnomethodological science of pointing or is he (Ashmore-like), simply using ethnomethology to cut away the basis for the very possibility of science without trying to found a new one? It seems to me that when Lynch turns the ethnomethodological critique on his fellow social scientists (as opposed to natural scientists), he should turn it on himself too and this would behove him to cease from social scientific generalization. But oddly, not only does he generalize about pointing, he goes on to follow Doing's 2011 paper in proposing a neo-Marxist, or interest theory, sociology of tacit knowledge in which he relaxes his strictures on generalization and treats a study of UK Victorian doctors and a study of Australian doctors in the 1970s as showing the same thing which is, incidentally, applicable to the notion of tacit knowledge in general! We are a long way from John and Jane Doe's actions on 16 May 1965. What is going on is that Lynch is "doing specific historical and contemporary circumstances". He is using the accusation of lack of context specificity, in the flexible way all such accusations can be used, to rule his work in and other work out. This is a place where a bit more reflexivity would help rather than hinder. 


\section{Thornton}

I like Thornton's characterisation of my second two meanings of "explication"building a machine to do the job and creating a scientific explanation - as "action at a distance". I'll use the phrase in my discussion of the Soler-Zwart critique. In the main, however, I suspect the right way to handle the disagreement between Thornton and I would be to engage in an exercise something like that found in the paper by Collins \& Reber [this volume, 135-154]. We should spend a long time exploring what we each mean by knowledge, etc. Let us jump straight to Thornton's concluding sentence:

Collins's broader account is of the nature of patterns or processes that might be known, not of the different ways in which they are known. It is pitched at the level of worldly patterns or ontology rather than the way they are known by epistemic subjects. Now that might be a perfectly fine area of inquiry. But it is not a discussion of tacit knowledge. [This volume, 106]

Those who read the Collins-Reber piece will see, what I think is, something similar: Reber, the psychologist is concerned with what is in peoples' heads, Collins is concerned with the nature of knowledge stuff and how it is transmitted and implemented.

Now I have to agree that what I am doing does not fit well with how most other analysts think about tacit knowledge and it happens that a good proportion of these other analysts are drawn from areas of psychology and philosophy which are closely allied. This close alliance is reinforced by a common concern with consciousness, qualia, and the like, all of which take the human experience as the central feature of the domain to be analysed. Hence, Thornton, if I understand him, not only has trouble with my notion of tacit knowledge but also any notion of tacit knowledge since when we have knowledge we are usually conscious of knowing something and this does not fit with the knowledge being hidden from us.

But what happened to me was that I just started to write about tacit knowledge, expecting, and promising others, to write a quick summary in four weeks, and found to my surprise, that I could not write about the tacit without understanding the explicit and, to my still greater surprise, that the explicit was the real mystery. This came about not from any determination to do things differently but because with my existing resources the words of the unfolding manuscript refused to lie quietly on the page.

I keep wanting to say that my treatment does not jibe with many of the psychologists and psychologically inclined philosophers because one of my central problems (after writing two books and many papers about artificial intelligence), is what kinds of knowledge-based performance can be reproduced by machines. But many of the group we are talking about also worry about artificial intelligence so a lot more disentangling would be needed to get to the heart of the matter. 
I could have resolved my problems in a Thornton-like way. I could have started with language instead of strings. If I had started with language and signs, then there would be no particular difficulty about explicit knowledgenot the kind of difficulty I struggle with-because languages, signs, icons, and so forth are already invested with meaning. But Polanyi has it right - the way that they are invested with meaning is tacit. So when one is dealing with signs etc., one is not dealing with explicit knowledge, one is already dealing with the explicit mixed with the tacit. In that case, the relationship between tacit and explicit knowledge would turn out to be simple - explicit knowledge is already invested with tacit knowledge and there is nothing to resolve. It would be, as I say in the book, circular. And one can see how circular it is by asking whether it helps with the problem of what a machine can do and immediately see that it helps in no way whatsoever.

So, where Thornton says that what I call knowledge is not really knowledge at all, I say, in that case it is time to change the way we use the word "knowledge". To classify tacit knowledge, to know the extent to which machines can mimic it, and to understand explicit knowledge, one must start from a different place. The way humans per se experience knowledge is one topic but the nature of tacit and explicit knowledge is another and to confuse them is to be confused about tacit knowledge too. I thought the example of bicycling in very low gravity had established this point.

I apologise for the fact that I also want to maintain the cross-cutting, and therefore confusing, idea that only humans should be called "knowers". Humans are, in another sense, continuous with animals and sieves when it comes to using knowledge without talking about it but I still do not want to call animals and sieves knowers. This is a bit messy. It is not a deep point, I just think that the term "knower" should be restricted to entities that are, in principle, capable of reflecting on what they are doing and are potentially capable of describing it. These are knowers in Thornton's and Reber's sense. But knowledge is a more general idea. You can have knowledge without knowing it and, therefore, without being a "knower".

\section{Turner}

While responding to Turner's elegant critique I will take the opportunity to mention his earlier review of TEK [Turner 2011] (Hereafter, T2011). T2011 starts with a generous assessment of this author's qualities and flaws. It goes on to a comprehensive and nearly completely accurate description of what is in TEK. But the punchline, and never has the term punchline been more appropriate, is:

[...] both the starting point of the argument and its conclusion are groundless. So is most of what comes between. [Turner 2011, $475]$ 
I could not help grinning. One of the most attractive things about our strange academic life is that it is possible to enjoy the work of one's critics even as in the film, Jurassic Park, the white hunter could not but appreciate the stalking skills of the velociraptors that were about to rip him apart. Such things concentrate the mind. Note that the analogy stops at the concentration and before the ripping apart.

I now want to correct a couple of small errors in the exposition part of T2011. Firstly, there is meant to be much less difference between digital and analogue strings than can be read from Turner's treatment. We experience them as different but I spend a lot of time saying that at the deepest level they are the same. Secondly, T2011 makes the same mistake as Lynch and others in thinking that I believe RTK and STK are of little interest because I call them "weak" and "medium" whereas I call CTK "strong". I also say that CTK is the irreducible heartland of the problem. Thus in T2011 we find:

Once the pretenders to the title "tacit knowledge" have been sent packing, the real thing we are looking for will be revealed. [Turner $2011,474]$

But, though CTK may be the most interesting category from a philosophical point of view, RTK and STK are always with us and are just as important from a practical point of view and mostly indistinguishable from CTK for practical purposes. Yes, they can be explicated in principle but I stress that only a bit of RTK can be explicated at any one time and that the explicated bit is a moving target. When we come to STK, it is just as necessary for balancing on your bike as it ever was, even though there is a sense in which it can be explicated. Indeed, in some ways RTK and STK are more interesting because, as ideas, they are more novel than CTK which was what was being explored a lot of the time under the old undifferentiated category of tacit knowledge.

T2011 advances two main objections to TEK's position. The second objection is repeated in his contribution to this volume and we can deal with it under that heading. The first objection is as follows:

The basic structure of the argument [of TEK] as a whole is this: Much of what passes for tacit knowledge, namely the individual part, can be done by or imagined to be done by machines; the rest cannot be done by machines, or at least machines can't be fluent at it, so this remainder must be collective. The reasoning is transparently faulty. This is why:

[...] The fact that machines can simulate something that humans do tells us nothing about how humans do it. This is a point Collins himself makes. So the entire discussion of string transformations is irrelevant: he gives us no reason to believe that what people do when they communicate has anything to do with strings, string transformations, or anything like it. This is just an analogy. [Turner 2011, 475] 
As far as I can see, and very uncharacteristically, Turner has gone completely wrong here. It is true that I frequently help the argument along by imagining some action being carried out by a machine. I might say something like:

so a salute is a mimeomorphic action whereas a greeting is a polimorphic action and one can see that it would not be difficult to build a saluting machine if you were crazy enough but there is no way of building a greeting machine.

Don't worry about what salutes and greetings are, just notice the logic of the argument. It is not that the fact that a certain action can be mimicked by a machine proves it is mimeomorphic, it is that the fact it can be mimicked helps one to see that it is mimeomorphic while the reason it is mimeomorphic will have been explained by other means - e.g., we always try to carry out a salute in the same way. It could not be the other way round or a tractor would always be proving that pulling something was always a mimeomorphic action but it isn't because when you have a tug-of-war with your lover you do it in a different way than with your deadly enemy. On the other hand, one is continually assailed by claims that the latest AI-based machines are executing polimorphic actions so the theory must be wrong. But then one has to examine these claims with special attention to discover if the machine is really doing the same thing as the human, which, to date, it never is. ${ }^{2}$ Turner seems to think I am using executability by machine in the way electricians use one of those little screwdrivers with a light in to find out if the current is live - it is either on or off. It can never be used this way but it is a powerful aid to thinking about these things - like, in Wales, looking out of the window to see if it is likely to rain in the near future. So that is why the first point in T2011 goes off the rails.

Then T2011 offers that this renders the entire discussion of string transformation irrelevant. I have no idea why Turner would say that. And he says that I provide no reason to believe that what people do when they communicate has anything to do with strings. But this seems completely bizarre. That communication is in terms of strings is almost definitional: it is just a physical description of what is going on causally when one person, say, speaks to another. How could I provide a reason for saying that when people communicate they use strings - I am simply picking one description of what they do as I might say, "when I look at a painting light is involved". Turner is saying something like Collins gives us no reason to think light is involved. Of course, I know how to "deconstruct" the idea that light is involved but I do not think that is what is at issue here.

2. It was Arthur Reber's suggestion that cars that could drive themselves had been developed that led to the paper by Collins \& Reber [this volume, 135-154]. Soler-Zwart also mention this possibility (see their paper note 8). Examined closely, such cars do not do drive themselves in a human-like way but are one more example of the gap between artificial intelligence and what it sometimes claims for itself. 
Now we can turn to Turner's essay in this volume (75-92) and, by default, the second criticism in T2011. What Turner really does not like is the idea of the social collectivity as a fundamental unit of explanation. I say things like, "knowledge is the property of collectivities", while Turner says collectivities do not exist, there are only social relations between individuals. Turner does valuable work in distinguishing between the two, noting that the word "social" is often used to cover these two very different things, something I have probably been guilty of myself. So let me make clear, as Turner also makes clear, that when we come to Collective Tacit Knowledge I am indeed talking of social collectivities, not just the social. Furthermore, I refer in TEK and elsewhere to "socialness":

It is only humans who have the ability to acquire cultural fluency. It is only humans who possess what we can call "socialness"- the ability to absorb ways of going on from the surrounding society without being able to articulate the rules in detail. [TEK, 125] ${ }^{3}$

Therefore there is a very clear division between us and when I say, in the introductory remarks to this piece, "Turner has gone straight for the core of the book and tried to explode its most basic principle", this is what I am referring to. It is the uncompromising nature of this attack that is so valuable because it forces us all to state our positions clearly, my contribution being to champion a very old fashioned position, something like that of Durkheim. ${ }^{4}$

The larger part of Turner's critique in this volume is a very long and detailed analysis of how social and collectivity-based explanations work, along with a scorecard comparing each. I'll adopt a Turner tactic and step back, trying instead to say what is going on in a simple way that I think Turner would agree with. Here we go! The collectivity approach provides parsimonious explanations of what we see going on in the world, with a non-parsimonious ontology - it introduces a "mysterious" new thing called the collectivity. It also finds great difficulty in explaining how individuals communicate with the new thing. The social approach has a parsimonious ontology, the only things it needs being individuals and their interactions. There is no special difficulty in explaining how individuals communicate with each other in the way there is difficulty in explaining how individuals communicate with the collectivity. And, crucially, it is possible to use the social approach to explain all that the collectivity approach explains even though it might be a bit more complicated.

3. See also [Collins 1998]. There is a possibility of terminological confusion here since Turner talks of the social as meaning the complex relationships between many individuals whereas I am implying something more "ontological" with the term "socialness".

4. And interestingly, an instance of yet another disagreement between myself and Latour (though it is really the old disagreement in another form), since Latour is nowadays championing Gabriel Tarde, who was Durkheim's rival, precisely in the matter, as Turner points out, of insisting on analysis in terms of the social as opposed to the collective. 
What this reveals, I believe, is a deep difference in my approach and Turner's approach to scientific explanation. I think this might reflect something different about our starting points (we have both ended by doing philosophy, or quasi-philosophy). My starting point is in fieldwork and practical problems whereas his starting point, as his critique exemplifies, is the philosophical canon: he deals on even terms with Kant and Quine whereas I am just thrilled to be mentioned in the same paragraph.

I think this difference might be closely related to what Reber and I call "Mismatched explanatory adequacy" [this volume, 135-154]. Turner and I just want different things from our explanations. What I value most is something that makes it easy for me to understand what I see going on around me while what Turner values most is something that does not introduce any unnecessary explanatory apparatus where it can be avoided. Indeed, Turner's desire in respect of this is so strong that he not only eschews collectivities, he eschews the whole idea of tacit knowledge, wanting to replace it with habits (see, e.g., [Turner 1994]). If that is indeed the case there is not much else to do except say why I don't share his desire and why I think my approach is better even though it does introduce a new, or at least quasi-Durkheimian, ontology. I do not think any of this is going to come out as a "proof" in the mathematical sense, just a discussion about the best way of going on. Therefore, what follows is more of a list of attempts to persuade, rather than an "argument" in the logical sense.

First, let us see if there are any successful scientific theories that might be said to have introduced suspect ontologies. Newton's theory of gravity springs to mind. It invented something you could not see, smell or touch that implied the mysterious action at a distance. But it wasn't a bad theory. We probably prefer Einstein's theory because it does not involve action at a distance or a mysterious thing that you cannot see, smell or touch but I don't think we want to say that in the intervening years between the invention of the idea of Newtonian gravity and Einstein's better conception it was only bad science that was going on even if the ontology was not parsimonious enough to meet certain philosophical standards. Though I would hesitate to compare myself with these famous men, I too am saying only that this equivalent to action at a distance (the notion of social collectivity) works (more on this below), and that there is nothing in the theory that says it could not one day be replaced by something better. I am very careful to claim only that at the moment we don't know what it is. To repeat, I cannot prove that Turner is wrong in any strong sense, it might be an immensely complex set of individual interactions, but to insist that this must be so because of an ontological preference is to give too much authority to philosophy over science. It seems to me to condemn us to going along in the same old way that has been failing us for decades without any impetus to see to the heart of the problem and try to think in new ways.

By the way, early in our email exchange, Reber (this volume) wrote to me: 
[Y]ou realize, of course, that living in America gives a very different tinge to this broad idea of collectivism in all and any instantiation. This crazy land is still wrapped up in an individualistic ideology and makes ideas like yours suspect - and not just as a particular sociological model. [Arthur Reber, private communication, 25 Nov 2012]

We oughtn't to forget the sociology of scientific knowledge entirely. ${ }^{5}$

Of course, we are paid by our universities to act as though "external" forces have no effect on our reasoning, so let us get back to the substance. The remaining points can be briefly set out. "Yes", the collectivist approach has enormous difficulty with explaining communication between individuals and the collectivity. But to me that is its strength. All the problems that we encounter with, for example, interdisciplinarity, "incommensurability", and the creation of intelligent machines that mimic polimorphic human actions, emerge precisely because we do not know how the communication works. I argue this over and over again. The reason that even a giant like IBM and Google cannot make a speech transcriber, or even a spell-checker, that works like a human being, is because we do not know how to plug intelligent computers into societies in such a way that they can suck their metaphorical blood. The developers of "intelligent machines" understand this in that they are now plugging their machines into the internet and, as a result, the machines are getting better at a restricted range of activities (such as IBM's "Watson" computer winning at "Jeopardy"). But they are still subject to the most colossal errors when it comes to what, for humans, are the most simple tasks, such as keeping up with slang. Here is something from 7 January this year (2013), which is about as recent as I can make it:

Two years ago, Brown attempted to teach Watson the Urban Dictionary. The popular website contains definitions for terms ranging from Internet abbreviations like OMG, short for "Oh, my God", to slang such as "hot mess".

But Watson couldn't distinguish between polite language and profanity - which the Urban Dictionary is full of. Watson picked up some bad habits from reading Wikipedia as well. In tests it even used the word "bullshit" in an answer to a researcher's query. Ultimately, Brown's 35-person team developed a filter to keep Watson from swearing and scraped the Urban Dictionary from its memory. But the trial proves just how thorny it will be to get artificial intelligence to communicate naturally. [http://tech.fortune.cnn.com/2013/01/07/ibm-watson-slang/]

Notice that it is IBM trying to make this work. We can assume they have pretty-well unlimited resources and, as the article says, they have a 35-person team working on it. We know that Google is trying to achieve similar things.

5. For a classic instance of this kind of explanation see [Forman 1971]. 
We know that such corporations and research teams in universities have been trying to achieve what they are trying to achieve here ever since the 1960s, when it was first claimed that it had been done with ELIZA. Over and over again during half-a-century it has been claimed that it has been done. And yet, to date, there is nothing that can survive the Turing Test for more than a couple of conversational turns - or succeed in even one turn if the judge knows how to ask the question.

We have a choice. We can say that what is needed is understood, it is just a matter of going on the same way until we get there, or we can say it is time to rethink the problem in a more thoroughgoing way. Turner may believe that the social and non-collective approach provides all the answers but I say that this half-century of experience suggests to me that it is time to start again with sociology, and that is not the milk-and-water sociology of individuals in interaction but the true sociology of the notion of the collectivity as the basic unit of explanation. Try it! It explains everything that you see going on around you that touches on the frontiers of artificial intelligence by pointing out that we don't know how to plug machines into society. It says that the problem of artificial intelligence, and I mean the "simple" problems, like building a human-like spell-checker, will not be solved by continuing in the current fashion. The social approach of Turner just does not give a reason why the huge effort over many decades has not worked; it just says do more of the same and we will get there. The collectivist approach may turn out to be wrong in the long term but even if it is, it concentrates the mind. And it concentrates the mind in the right place. It tells us what to look for when the next falsely-promised generation of fully "human-like" machines comes along. For those who are willing to learn the lesson, it tells how to build much more successful intelligent machines: give up trying to make humans and make "social prosthesis" [Collins 1990, 14], with clearly defined areas for humans to do the "repairs". And it tells us that if we really want to make automated humans then it is their interface with society that is going to be the key. That is the reason I prefer the collectivist approach to Turner's, and the extra object we have to purchase, like gravity for Newton, is well worth the ontological price we have to pay for it.

As I said, it gives me a thrill to be mentioned in the same paragraph as Kant and Quine even if it is the case that this "major figure" in the naturalization of science (thanks Steve) now finds himself inadvertently rooting for his onetime antagonist, Kant, instead of his proper champion, Quine. As explained in the introduction, I do not think there is any irony here, I think it is simply a matter of choosing to look one way rather than the other. But I have not been trained as a philosopher. 


\section{Soler \& Zwart}

Soler \& Zwart have taken a very different approach to that of the other critics. They have started with what the book is trying to do and set out to discover technical errors, correct them, and do it better; their critique, as they so aptly put it, is written "from the inside". There is a lot of enormously carefully worked out critical detail in the Solar-Zwart (SZ) paper and theirs is the only contribution that has caused me to think about doing some things differently. If there is ever a new edition of TEK, some of what they argue will find its place therein, probably in the new material at front or back. What I particularly like about SZ is that they have not only found problems but tried to solve them in a positive way and in a way that leaves the original terminology as little altered as possible.

But SZ have adopted a very technical approach to the work, with complicated notations which make it difficult to read. Because what they say is important I will start by trying to pull out the main points of their argument in plainer language. There may be some losses but I think the subsequent discussion will be more accessible. ${ }^{6}$ The ordering in the list below does not correspond exactly to the ordering in the SZ paper nor to my subsequent discussion but I think it works.

\subsection{Collins's summary of main Soler-Zwart points}

1. The "unrecognized knowledge" element of RTK has nothing to do with the relations between the parties trying to transfer the knowledge (in the way that secrets do have to do with relations between the parties). Therefore the term "relational" would be better replaced by another term such as "contingent" or "accidental".

2. The reason that there is confusion is that the tacitness of STK and CTK is related to their location, in brain and muscles and society respectively, whereas RTK can cover any topic and its tacitness is related to various contingencies.

3. One implication of the idea of RTK is that the contingency is local. What is RTK in one place is explicit knowledge in another.

4. Elements of Somatic Tacit Knowledge can also be rendered explicit and whether they are is also an accidental or contingent matter. Therefore,

6. Soler (private communication) says that aside from point 2 , these points are a close but not exact fit to their argument but they are close enough to support what follows. In the case of point 2 they say their important argument has to do with the difference between reasons and topics. I find their point hard to follow and, on my reading, my response to what they say is apt. Readers will have to decide if I have missed the deeper point both here and in other places. I would not be surprised if our dialogue were to continue. 
in so far as Relational Tacit Knowledge exists there must also be relational Somatic Tacit Knowledge.

5. This opens up the possibility that there could also be relational Collective Tacit Knowledge. When we describe some of the differences between national driving habits we appear to be rendering some CTK explicit and this would exemplify the possibility.

6. The relations that can prevent a piece of RTK becoming explicit have sometimes to do with individual motivations and this is closer to the idea of social rather than collectivist (I am borrowing Turner's vocabulary).

7. It is possible for there to be individual tacit knowledge - e.g., what might be in the head of a pioneering scientists who has just made a breakthrough but cannot explain it. Collins deals only with group tacit knowledge.

8. Given the reformulation that follows from the above clauses, it is possible to construct a new dynamics of the evolution of tacit knowledge into explicit knowledge.

I will start by eliminating points that I think are wrong or pull in unproductive directions and narrow down to the important points and what I think should be done about them.

\subsection{Points that I do not think are helpful}

\section{Point 1: The "Relational" in RTK: should it be something like "Contingent"?}

RTK began life as "Contingent Tacit Knowledge" just as SZ would prefer. It changed to RTK quite late in the process simply because I wanted it to have a distinct acronym and CTK was already in use for Collective Tacit Knowledge. Therefore I cast around for another term that would fit the requirement and came up with "relational". I could well have picked one of their suggestions: "accidental". It might have been better if I had. But I do not think it is a matter of as much importance as they say it is. I think they are bit harsh on "relational" because they seem to have interpreted it more narrowly than I intended. They interpret it as to do with the relationship between the transmitter, $A$, and the receiver, or potential receiver, $B$, of a piece of knowledge but I always meant it has to do with relations between wider sets of human beings. Thus, if relations between scientists building lasers had been different what was the RTK of the length of the top lead might have been explicit while something else might have been tacit. In other words, where they say "history", I say, "yesterday's set of human relations", so "relational" still applies. I think once it is seen that the relations are intended to be relations in the wider community rather than between " $A$ and $B$ " many of their objections to the term disappear. But it does not matter too much so long as we all still know what we are talking about. 


\section{Point 5: Can there be relational Collective Tacit Knowledge?}

I am going to argue that their idea of relational somatic TK is important but that relational CTK is best forgotten about. The very essence of CTK is that it is the property of the collectivity and therefore cannot be explicated for the consumption of the individual. As SZ point out, however, it is possible to say something expository about CTK. Thus I can summarise the difference in driving patterns in different countries. But I believe this is best not looked at as the explication of CTK but as providing "hints", or "coaching rules", which are an aid to the acquisition of CTK. One reason is that this keeps the scheme neat and consistent. Another reason is that if we take this kind of thing as the explication of CTK we will go wrong. Searle's Chinese Room is an example of how we could go wrong. Searle thinks he has invented a scheme that involves the explication of the TK embedded in natural languages. But he has not. What he has done is taken a frozen moment of language and represented that in look-up tables. The Chinese Room would degrade as fast as the language changes. $^{7}$ The Chinese Room is best thought of as comprising a huge number of not very efficient coaching rules on how to speak Chinese. The same goes for traffic rules: at best, that is without even thinking about the rules regress, they represent a frozen moment in time and if one tried to apply them without also being a parasite on traffic society, one will find oneself at risk of going badly wrong.

\section{Points 7 and 6: What should we do with the individual?}

Removing the possibility of relational CTK makes everything simpler and so does removing individual TK-ITK as we might label it. ITK, as SZ put it forward, seems to have something in common with what Polanyi wanted to say about the special insight of scientists who could jump to a conclusion before they knew why. I am convinced that this ability exists. Indeed, I often cite my "instinct" that this will work out or that this won't work out long before I know how to show it and I am mostly right. Nevertheless, I do not think that ITK should be part of the scheme even though it might be a good topic for psychologists or some kinds of philosophers. The reason is that the scheme is based in a collectivist (Turner's "social" works just as well here) notion of knowledge.

This preference goes all the way back to the sociology of scientific knowledge where we discovered that the way to handle knowledge was to treat it as the product of society and thus avoid any discussion of what it would be like to have a private science (or private language). Only by removing scientific knowledge from the discourse of "individual genius" could we find a way to analyse it. We could understand paradigms, which were social entities, but

7. Continually updating it merely seems to solve the problem by passing it to human updaters who are embedded in society. 
we did not have to deal with geniuses, cranks or eccentrics. This attitude carried forward very productively into the construction of the Periodic Table of Expertises [Collins \& Evans 2007], where the meaning of expertise was equated with the acquisition of the tacit knowledge associated with an expert domain, not the expertise of individuals. Of course, some individuals are more expert than others within expert domains and I have tried to represent this with the Z-axis on what I call the "Expertise Space Diagram" [Collins 2013], but even this does not deal with the pioneering, or crazy, individual. I think individuals are best set aside for the sake of holding the world of tacit knowledge together.

To go back to point 6 , though it may be the case that sometimes RTK is TK because of the personal interrelationships of individuals, I do not think this adds anything much to the general points being made.

\subsection{Points that seem correct to me}

\section{Points 2 and 3: RTK differs in formation from STK and CTK and RTK varies with locality as well as with time.}

SZ show that the reason RTK is tacit is contingent in respect of the topic it deals with whereas the reason that STK and CTK are tacit had to do with the substance of the knowledge. I had never "seen" this. In retrospect it is obvious because RTK is a residual category. The history of this is that I struggled and struggled to make some sense of the categories until I came up with the residual RTK that gathers together all the knowledge that has no special reason for being tacit but is tacit, to use SZ's term, for "accidental" reasons.

SZ have also done a great job in clarifying that RTK is local, not only temporally but also spatially. I think this was always implicit in the book but, as a result of their analysis, I have a much clearer image in my mind. I now see RTK as a wide river of tacit knowledge with islands of explicit knowledge popping up here and there and slowly developing into more extensive territories. I had the idea of RTK as a narrow stream, continually building land but without diminishing the flow of water. I now see that there is another dimension of variation which is possible because it is a wide river and that the extent and position of the new lands can be different across the flow.

\section{Point 4: Some STK is also relational}

That, for me, STK is also relational is SZ's most telling point; I had completely missed it. It being the case that STK is explicated by doing science or engineering it is contingent on whether the science and engineering get done and in my acronym-preserving language it is, therefore, a matter of social relations between scientists and engineers. 


\subsection{A solution}

I want to avoid anything as complicated as SZ's notation because I want the concepts to have a wide audience. In the last two weeks I have spoken about these things to audiences as diverse as software testing engineers and musicologists along with theatre directors and it would be a shame if the work were made difficult to access.

What we are trying to do here is characterise different types of tacit knowledge so that people can see what follows from their own involvement with the types. It seems to me that the one serious flaw that SZ have uncovered is the last one: the term "relational" covers both RTK and some of STK. But for the classification scheme to work it does not have to be based on only one principle. All we need to say is that RTK is simply relational whereas STK is both relational and somatic. In other words, the description becomes multi-stranded.

If we accept this, we can take the opportunity to add a third strand. Thornton calls the second two categories of explication that are found in TEK's Table 4 [TEK, 81], "action at a distance". That is a nice phrase because it captures the fact that in the case of the first two categories: "Explicable by transformation" and "Explicable by elaboration", it is the communicator who mostly is in control of the process. In the case of the second two categories: "Explicable as mechanization" and "Explicable as [scientific] explanation", it is mostly others who are doing the explication, not the communicators. I think the four categories do represent the ways we talk and think of something being explicated and, as SZ point out, there is no clash between them-we just talk of something being explicated in ways 1 and 2 or 3 and 4 . Nevertheless, it is not a bad idea to bring out the different "feel" of two pairs of categories.

With these three strands in mind we can add some detail so as to characterise tacit knowledge as in Table 1.

\begin{tabular}{|l|l|l|l|l|}
\hline & RTK & S-l-TK & S-a-TK & CTK \\
\hline Relationality & \multicolumn{2}{|l|}{ Relational } & \multicolumn{2}{l|}{ Topic driven } \\
\hline Explicability & Direct & Distant & \multicolumn{2}{l|}{ None } \\
\hline
\end{tabular}

Table 2: Multi-stranded description of types of tacit knowledge

The table retains the basic three-way division but enriches it following what we have learned. What I have given more salience to, however, is the distinction between Somatic limit and Somatic affordance Tacit Knowledge (Sl-TK and S-a-TK). This is because this division corresponds to other aspects of the multi-strand characterisation.

Somatic limit Tacit Knowledge, it will be remembered, has to do with the inability of humans to follow sets of rules such as describe how to balance on a bicycle because their brains are not fast enough (in other cases it might be 
that their bodies are unsuitable). Somatic affordance Tacit Knowledge, it will be recalled, is the opposite. It refers to the fact that certain activities can only be executed by entities constructed of the right materials - for example, the elasticity of my sinews may afford a delicate action such as picking up an egg without breaking it whereas this would be impossible to achieve in a robot made of metal alone. SZ correctly point out that STK is relational but it is not so clear that this applies to Somatic affordance TK. To build a machine that reproduces S-a-TK it would be necessary to reproduce the materials of the human body or brain and this is so much like copying, rather than reproducing in another form, that it does not seem like explication. After all, one does not say that photocopying a printed page is explicating it! One might argue that if one could explain the qualities of the materials of body and brain that made it impossible to reproduce their performance using other materials, one might be doing explication of a scientific explanation kind, but it is a difficult point. So to keep things simple, S-a-TK will be kept with CTK in the inexplicable category, as indicated in the bottom line of Table 1.

S-a-TK and CTK are, as SZ point out, tacit in virtue of substance - one being located in the material of the body and one being located in society. But as the second line of the table indicates, RTK and S-l-TK both have a relational dimension.

The last line uses Thornton's term to set out the way that this table relates to Table 4 in TEK. Much of the time, when RTK is being explicated, it is being done by the communicators in a "direct" way. When, however, it is being worked out that the top lead of the TEA-laser should be less than 8 inches long, then the explication is "action at a distance" or, simply, "distant". The same applies to S-l-TK. Thus Table 1 preserves the main three-way distinction but is enriched to take into account aspects of the relationship between the three that my critics have brought out.

\section{Point 8: The dynamics of explication}

There are a number of ways in which I depart from SZ's attempt to develop a dynamics of explication. As has already been discussed, I do not believe it is wise to talk of any of CTK becoming explicated; we do not want to wind up saying that the guide-book to France contains France's culture nor that the French dictionary contains French. But there is a deeper and more revealing problem. SZ's dynamics begins with what they call a "no-production and nolosses" clause. They say: "these two conditions are unrealistic, but we use them for the sake of analytical clarification". I hate it when I put forward a thought experiment and someone replies that the assumptions are unacceptable; in a thought experiment one should be able to make any assumptions one likes. But the no-production and no-losses assumption actually changes the question. If the society we are imagining is completely static then it becomes identical to the frozen moment of language which is what (I claim) Searle's Chinese Room represents. It is possible to explicate a frozen moment of a society in a 
Chinese Room type of way. So a dynamics that works on the basis of frozen moments is not telling us anything about CTK. The same argument applies to STK: I cannot imagine what it would be like for humans not to be continually developing new bodily skills.

My dynamics would have no explication of CTK and, I think, no explication of S-a-TK (for the reasons given above). Where explication was possibleRTK and S-l-TK - I think the new islands of explication in a wide river of tacitness is the right model.

\section{Conclusion}

What does TEK try to do? In my introductory chapter to this volume [25-39], I suggest that one of the things it does is to bring the extraordinary nature of explicit knowledge to the fore. But none of my critics have chosen to discuss the analysis of explicit knowledge in any detail. The second thing that TEK tries to do, which was also explained in the introductory essay, is to be an antenna that can pick up the ephemeral signal of the otherwise invisible, tacit knowledge. It has been 50 years since Polanyi introduced the term and, though it has been used, notably in management and science studies, and investigated (see Reber's work in Collins \& Reber, [this volume, 135-154]), the concept has remained mysterious; people worry about how you can say anything about a concept that has no visible contents. In so far as philosophers have explored the concept, their aim has often been to try to do away with it; Turner, for example, argues that we do not need the concept, all we need is the idea of habits. ${ }^{8}$ TEK tries to show, for what I believe is the first time, that different things can be meant by tacit knowledge and that there are three basic kinds. It takes the concept seriously and tries to analyse it and move it forward. It tried to give us something to discuss, not simply to dismiss.

Unfortunately, in this volume, only Soler \& Zwart really take up the challenge. They take it up so effectively that they uncover some serious problems. What I have tried to do is fit their findings into the scheme in such a way that the original three-way classification is enriched rather than weakened. In any case, I still think the three-way classification still exhausts the world and cuts it at, or very close to, the joints. This exercise, thanks principally to SZ, has revealed that one can cut things up in a slightly more refined way and cook a still more satisfying meal.

8. Thornton also wants to question the very possibility of a tacit knowledge and there are many more philosophers working along the same lines. 


\section{Bibliography}

Ashmore, Malcolm

1989 The Reflexive Thesis: Wrighting Sociology of Scientific Knowledge, Chicago: Chicago University Press.

Collins, Harry

1985/1992 Changing Order: Replication and Induction in Scientific Practice, Chicago: University of Chicago Press, $2^{\text {nd }}$ ed., $1^{\text {st }}$ edition Sage publications, 1985.

1990 Artificial Experts: Social Knowledge and Intelligent Machines, Cambridge, MA: MIT Press.

1998 Socialness and the undersocialised conception of society, Science, Technology and Human Values, 23, 494-516.

2010 Tacit and Explicit Knowledge, Chicago: University of Chicago Press, [TEK].

2013 Three dimensions of expertise, Phenomenology and the Cognitive Sciences, 12(2), 253-273. doi:10.1007/s11097-011-9203-5.

Collins, Harry \& Evans, Robert

2007 Rethinking Expertise, Chicago: University of Chicago Press.

DoIng, PARK

2011 Tacit knowledge: Discovery by or topic for science studies?, Social Studies of Science, 41(2), 301-306. doi:10.1177/0306312710397690.

Forman, Paul

1971 Weimar culture, causality, and quantum theory, 1918-1927: Adaptation by German physicists and mathematicians to a hostile intellectual environment, Historical Studies in the Physical Sciences, $3,1-115$.

Latour, Bruno \& Woolgar, Steve

1979 Laboratory Life: The Social Construction of Scientific Facts, London; Beverly Hills: Sage.

Turner, Stephen

1994 The Social Theory of Practices: Tradition, Tacit Knowledge and Presuppositions, Cambridge: Polity Press.

2011 Starting with tacit knowledge, ending with Durkheim?, Studies in History and Philosophy of Science, 42(3), 472-476. doi:10.1016/ j.shpsa.2011.03.002. 